\title{
Hybrid Generative Gear Manufacturing
}

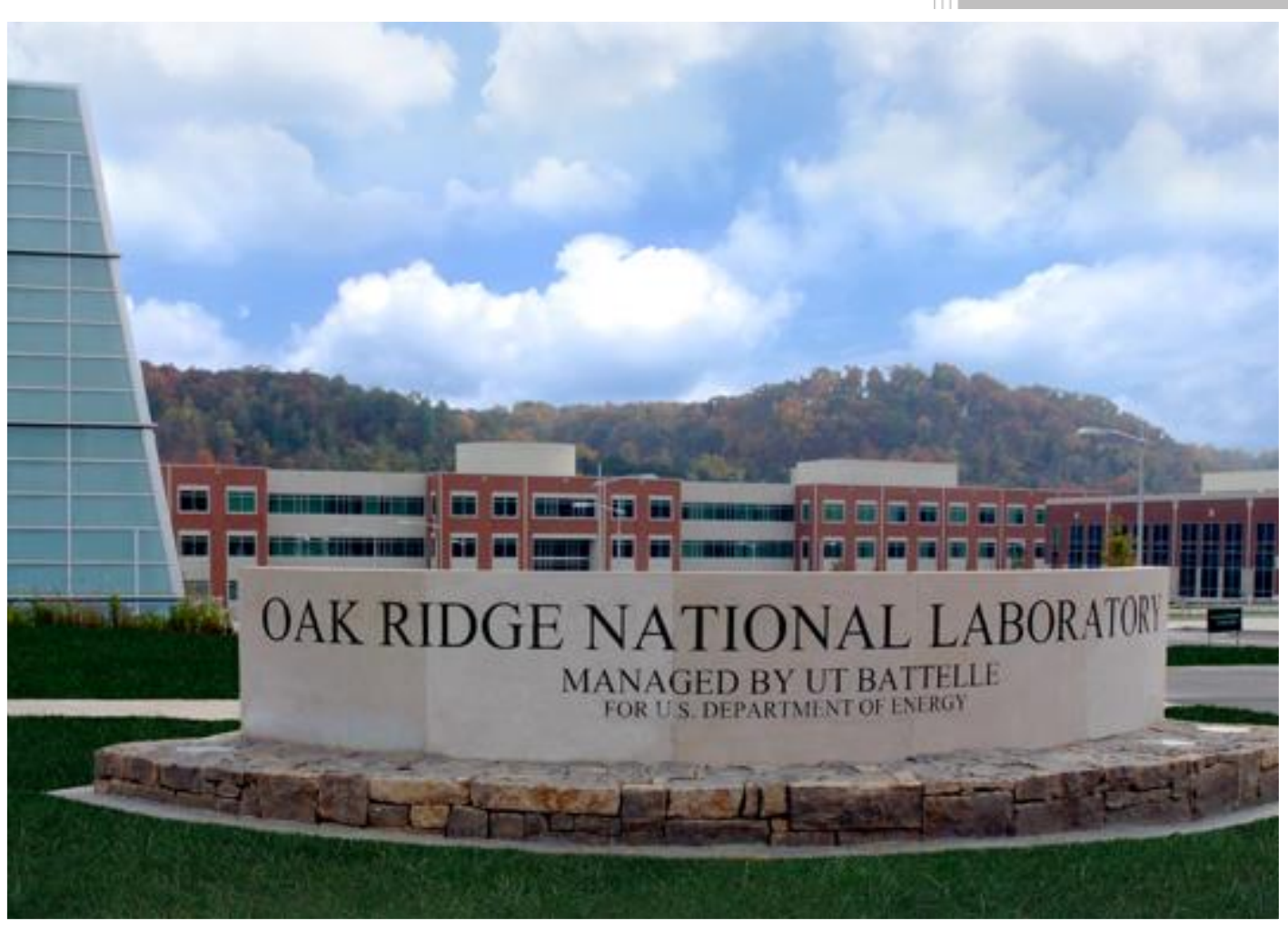

\section{CRADA FINAL REPORT} NFE-17-06744

Peeyush Nandwana

September 2019

Approved for Public Release. Distribution is Unlimited. 


\section{DOCUMENT AVAILABILITY}

Reports produced after January 1, 1996, are generally available free via US Department of Energy (DOE) SciTech Connect.

Website http://www.osti.gov/scitech/

Reports produced before January 1, 1996, may be purchased by members of the public from the following source:

National Technical Information Service

5285 Port Royal Road

Springfield, VA 22161

Telephone 703-605-6000 (1-800-553-6847)

TDD 703-487-4639

Fax 703-605-6900

E-mail info@ntis.gov

Website http://www.ntis.gov/help/ordermethods.aspx

Reports are available to DOE employees, DOE contractors, Energy Technology Data Exchange representatives, and International Nuclear Information System representatives from the following source:

Office of Scientific and Technical Information

PO Box 62

Oak Ridge, TN 37831

Telephone 865-576-8401

Fax 865-576-5728

E-mail reports@osti.gov

Website http://www.osti.gov/contact.html

This report was prepared as an account of work sponsored by an agency of the United States Government. Neither the United States Government nor any agency thereof, nor any of their employees, makes any warranty, express or implied, or assumes any legal liability or responsibility for the accuracy, completeness, or usefulness of any information, apparatus, product, or process disclosed, or represents that its use would not infringe privately owned rights. Reference herein to any specific commercial product, process, or service by trade name, trademark, manufacturer, or otherwise, does not necessarily constitute or imply its endorsement, recommendation, or favoring by the United States Government or any agency thereof. The views and opinions of authors expressed herein do not necessarily state or reflect those of the United States Government or any agency thereof. 
Materials Science and Technology Division Advanced Manufacturing Office

\title{
Hybrid Generative Gear Manufacturing
}

\author{
Authors \\ Peeyush Nandwana (ORNL) \\ William H. Peter (ORNL) \\ Hao Peng (ITAMCO) \\ Joel Neidig (ITAMCO) \\ Date Published: \\ September 2019 \\ Prepared by \\ OAK RIDGE NATIONAL LABORATORY \\ Oak Ridge, Tennessee 37831-6283 \\ managed by \\ UT-BATTELLE, LLC \\ for the \\ US DEPARTMENT OF ENERGY \\ under contract DE-AC05-00OR22725
}

Approved For Public Release 


\section{CONTENTS}

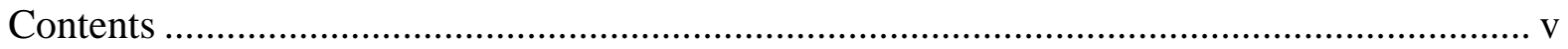

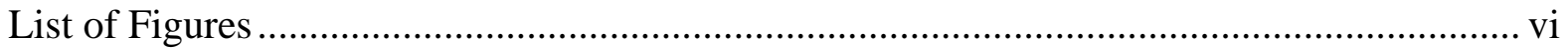

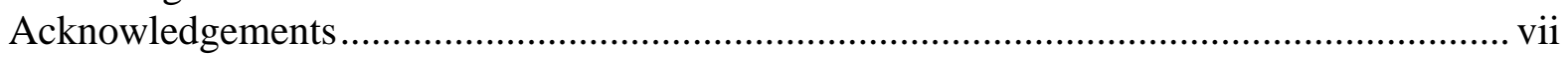

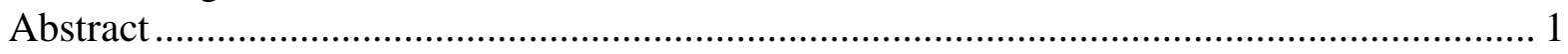

1. Collection of Pedigree AM Data for Analysis and Correlation......................................... 1

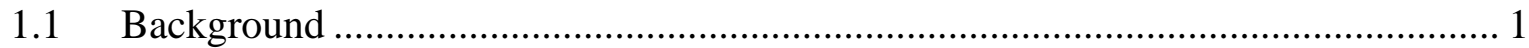

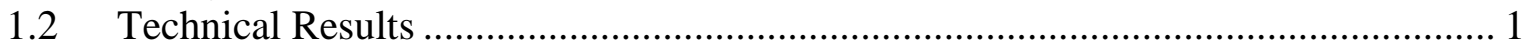

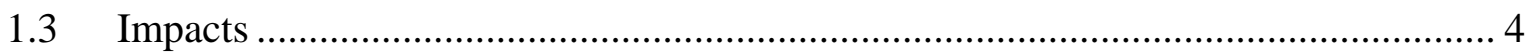

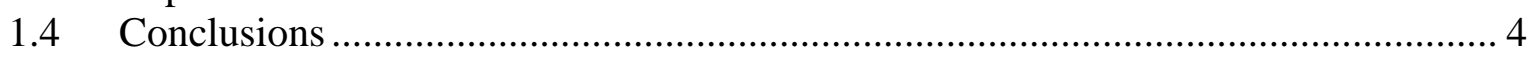

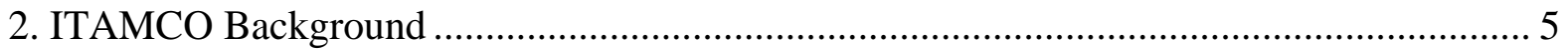




\section{LIST OF FIGURES}

Figure 1. Schematic of Ferrium C64® builds deposited for tensile testing on the EOS 290

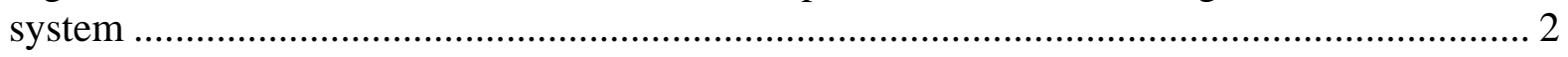
Figure 2. Summary of the YS, UTS, and elongation as a function of build orientation and

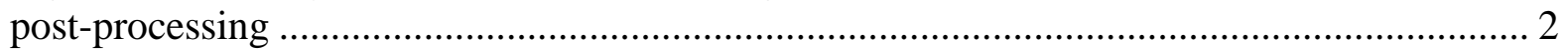

Figure 3. Prototype Ferrium C64® gear with mesh in the hub with solid band and teeth ....... 3 Figure 4. Comparison of the microstructure of pure Ti64 and Ti64-B 4 C showing streaks of TiB particles in the matrix ......................................................................................... 3 Figure 5. The graded Ti64/Ti64-B 4 C band deposited on a pure Ti64 bar stock that will be machined to final gear morphology .............................................................................. 4 


\section{ACKNOWLEDGEMENTS}

This CRADA NFE-17-06744 was conducted as a Technical Collaboration project within the Oak Ridge National Laboratory (ORNL) Manufacturing Demonstration Facility (MDF) sponsored by the US Department of Energy Advanced Manufacturing Office (CPS Agreement Number 24761). Opportunities for MDF technical collaborations are listed in the announcement "Manufacturing Demonstration Facility Technology Collaborations for US Manufacturers in Advanced Manufacturing and Materials Technologies" posted at http://web.ornl.gov/sci/manufacturing/docs/FBO-ORNL-MDF-2013-2.pdf. The goal of technical collaborations is to engage industry partners to participate in short-term, collaborative projects within the Manufacturing Demonstration Facility (MDF) to assess applicability and of new energy efficient manufacturing technologies. Research sponsored by the U.S. Department of Energy, Office of Energy Efficiency and Renewable Energy, Advanced Manufacturing Office, under contract DEAC05-00OR22725 with UT-Battelle, LLC. 



\begin{abstract}
Oak Ridge National Laboratory (ORNL) and Indiana Tool \& Manufacturing Company, Inc. (ITAMCO) partnered to fabricate hybrid generative gears that are supposed to be $20 \%$ lighter than conventional gears without compromising strength and wear resistance. A two-pronged approach was taken to fabricate hybrid gears, the first one leveraged a design modification to deploy a mesh structure to reduce weight whereas the second approach involved fabricating the gears with a Ti64- $\mathrm{B}_{4} \mathrm{C}$ composites for increased wear resistance. In the first approach, the gear material was a proprietary steel alloy, Ferrium C64®, and the focus was to demonstrate weight reducing by leveraging additive manufacturing to deposit fine mesh structure. In the second case, the focus was on material development for gears fabricated via directed energy deposition (DED).
\end{abstract}

\title{
1. HYBRID GENERATIVE GEAR MANUFACTURING
}

This phase 1 technical collaboration project was started on June 26, 2017 and was completed on June 25,2019 . In this project, ITAMCO focused on gear weight reduction by depositing mesh structures for the gear hub while depositing solid gear bands in near net shape. These would be further machined to final surface finishes. On the other hand, ORNL's focus in the project was to develop hybrid materials for light weight gear applications and focused on Ti64-TiC/TiB composites for depositing the band of the gear that can be subsequently machined.

\subsection{BACKGROUND}

Indiana Tool and Manufacturing Company (ITAMCO) is a medium size advanced manufacturing and technology firm with a focus on manufacturing gears and other components for industrial, defense, oil and gas, and mining and heavy construction industries. ITAMCO also manufactures custom gearboxes. This project between ITAMCO and Oak Ridge National Laboratory (ORNL) focused on hybrid generative gear manufacturing for reducing gear weight by as much as $20 \%$ without compromising the integrity of the structure. To this effect, a two-pronged approach was deployed. The first approach focused on ITAMCO evaluating a proprietary steel, Ferrium C64 ®, instead of conventional steels for gear fabrication owing to improved wear resistance offered by Ferrium C64®. The weight reduction was achieved by redesigning the gear itself and fabricating the gear geometry via laser powder bed fusion. In the second approach, ORNL focused on developing hybrid materials solution for gear manufacturing wherein the gear teeth were fabricated using $\mathrm{B}_{4} \mathrm{C}$ as reinforcing phase in a titanium matrix for enhanced wear resistance while fabricating the gear hub and bad with Ti-6Al-4V, commonly referred to as Ti64, for retention of fracture toughness and fatigue strength. For the study Ferrium C64® coupons were deposited and their monotonic tensile behavior was characterized while for Ti64- $\mathrm{B}_{4} \mathrm{C}$ hardness testing and microstructure analysis was conducted. Finally, prototype gear components were fabricated using both materials and are currently being machined to final surface finish.

\subsection{TECHNICAL RESULTS}

In the Phase 1 of this study, the first part consisted of deposition and mechanical characterization of Ferrium C64®. The material was deposited using an EOS M290 laser powder bed system. To determine any possible anisotropic behavior, as is common with most fusion based additive 
manufacturing (AM) processes, the builds were deposited in horizontal, vertical and $45^{\circ}$ angle with respect to the substrate. Figure 1 shows a schematic of the tensile bars deposited for tensile testing.

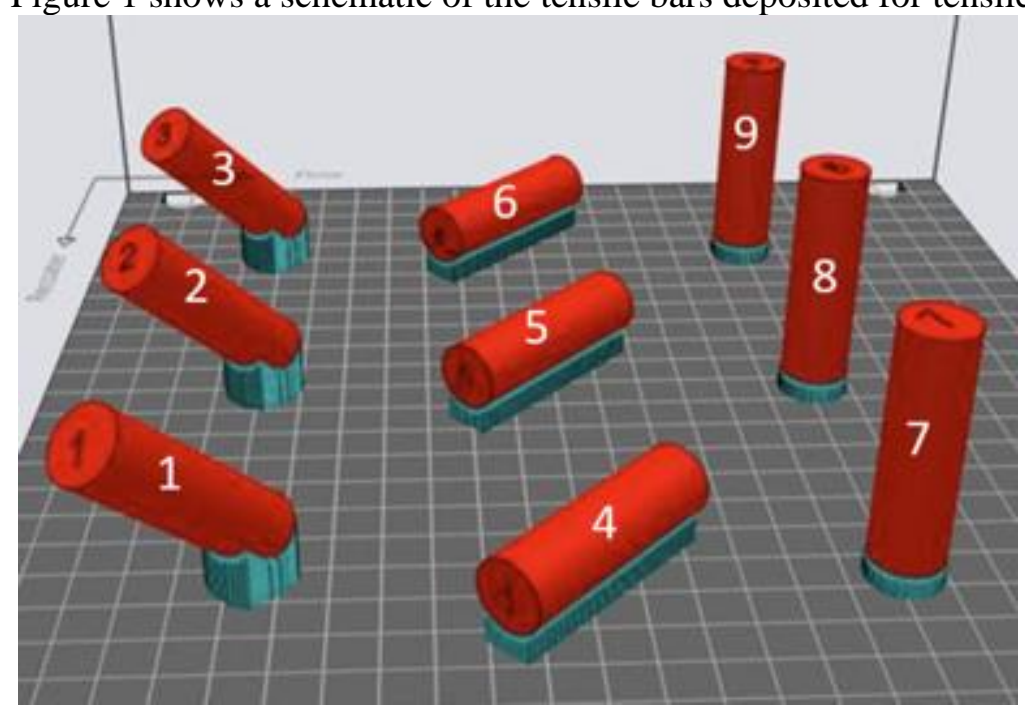

Figure 1 shows the schematic of Ferrium C64® builds deposited for tensile testing on the EOS 290 system

Among these tensile bars, one bar in each direction was tested in as-deposited condition to establish the baseline properties whereas the other samples were subjected to hot isostatic pressing and heat treatment prior to testing. The yield strength (YS) vs. elongation and ultimate tensile strength (UTS) vs. elongation plots are summarized in Figure 2. To be noted is the drop in the YS and UTS after heat treatment, possibly due to microstructural coarsening. There is a maximum standard deviation of 5\% in the YS and UTS after heat treatment. Heat treatment appears to have an improvement in ductility, possibly due to a combination of a coarser microstructure and pore closure resulting from HIP. However, even in asfabricated condition, orientation does not appear to play a significant role in governing the tensile behavior and the properties are isotropic. A more in-depth microstructure analysis is required to understand the impact of post-processing on the tensile properties.
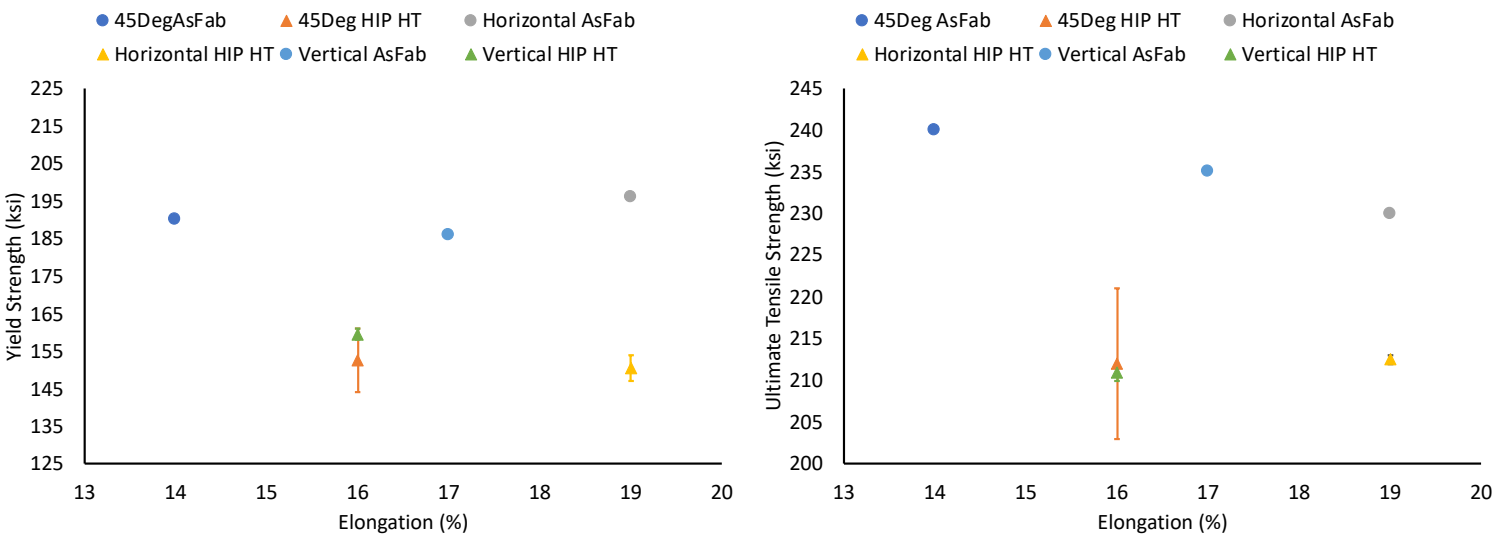

Figure 2 summarizes the YS, UTS, and elongation as a function of build orientation and post-processing

Owing to the crack-free fabrication of tensile coupons, a prototype gear geometry with mesh structure was fabricated and is shown in Figure 3. The gear was designed based on optimization of stress distributions to mimic those experienced by the gear in service. 


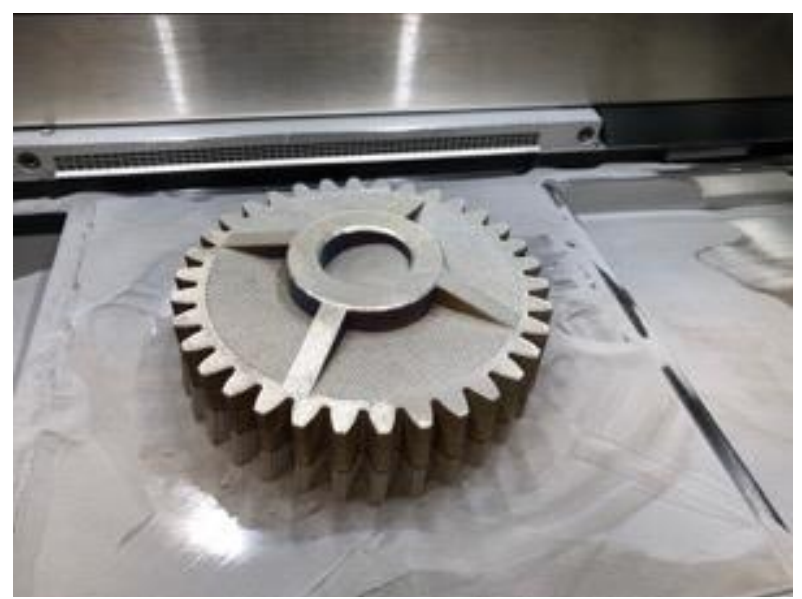

Figure 3 shows the prototype Ferrium C64® gear with mesh in the hub with solid band and teeth

While weight reduction can be achieved via topology optimization, on a production scale it would be time consuming or near impossible to machine the mesh structure of the gear to final surface finish. The surface roughness in as-deposited condition for most laser powder bed fusion technologies is large enough to cause crack initiation under high cycle fatigue loading. However, the efficacy of such a design can be determined only via fatigue testing of the gear and was beyond the scope of the current work. Thus, a materials solution was explored with regards to lightweighting of the gears. A directed energy deposition (DED) blown powder system was used to fabricate gears with Ti64 hub and band while having graded deposits to fabricated gear teeth reinforced by $\mathrm{B}_{4} \mathrm{C}$. In order to make the hybrid gear, one of the hoppers was loaded with pure Ti-6Al-4V powders and the other hopper was loaded with a blend of Ti64$0.2 \mathrm{~B}_{4} \mathrm{C}$ (weight\%). Small scale cubes with $25 \mathrm{~mm}$ cross-section and $25 \mathrm{~mm}$ in height were deposited for microstructure characterization. During melting $\mathrm{B}_{4} \mathrm{C}$ reacts with the excess titanium to form $\mathrm{TiB}$ and $\mathrm{TiC}$ per the following exothermic reaction

$5 \mathrm{Ti}+\mathrm{B}_{4} \mathrm{C} \rightarrow \mathrm{TiC}+4 \mathrm{TiB}$

Based on the weight $\%$ calculations, there was about $0.043 \%$ carbon and $0.157 \%$ boron in the Ti64/B $\mathrm{B}_{4} \mathrm{C}$ composite. Although, the $\mathrm{B}_{4} \mathrm{C}$ decomposition reaction should result in $\mathrm{TiC}$ and $\mathrm{TiB}$ formation, the carbon concentration is too low to form TiC. Based on the Ti-C and Ti-B phase diagrams for simplicity, the carbon is very likely to be present as a solid solution owing to its higher solubility $(0.4 \mathrm{wt} \%)$ in $\alpha-\mathrm{Ti}$ compared to boron that has practically no solubility $(<0.005 \mathrm{wt} \%)$ and tends to precipitate out as TiB at room temperature ${ }^{[Y o l t o n, ~ J O M(2004) ~ 56-59]}$. Figure 4 compares scanning electron micrographs captured using a Zeiss EVO LS $15 \mathrm{~W}$ scanning electron microscope for base Ti64 and Ti64-B ${ }_{4} \mathrm{C}$ region.

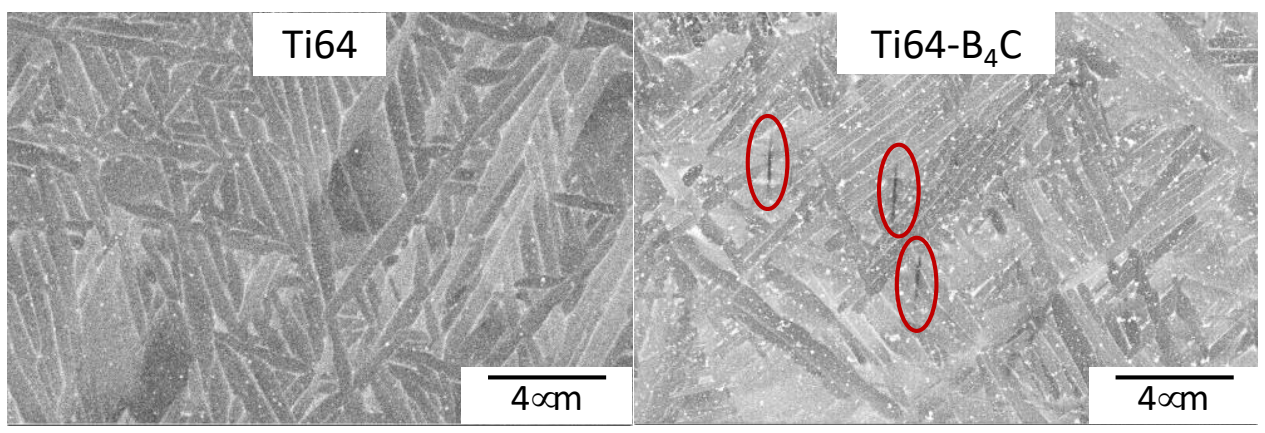

Figure 4 compares the microstructure of pure Ti64 and Ti64- $\mathrm{B}_{4} \mathrm{C}$ showing streaks of TiB particles in the matrix (shown in red highlights)

Based on the micrographs, to be noted is the presence of basketweave $\alpha$ in case of pure Ti64. This morphology is reported in DED systems and has been systematically studied by Sridharan et al [Sridharan et al. 
JOM 68 (2016) 772-777]. On the other hand, in the sample fabricated using the Ti64-B 4 C blend, TiB particles are visible as needle like shapes. This is the most common morphology for these particles ${ }^{\text {[Nandwana et al. Scripta }}$ Materialia 66 (2012) 598-601]. No discernible TiC could be observed in the micrographs, which is in line with the expectations that $\mathrm{C}$ would most likely be present as a solid solution owing to its small concentration $(0.043 \%)$ and higher solubility in $\alpha$ phase $(0.4 \%)$. At such low volume fractions of TiB, no cracking was observed. Ideally, the whole gear hub, band, and teeth would be deposited using the DED system. However, being a slow process, it would have taken unreasonable long to deposit a solid structure and at the same time losing the advantage of AM. Thus, the process was further hybridized in terms of using a wrought Ti64 bar stock of the required diameter. The band was deposited on top of the bar stock with composition grading from pure Ti64 to Ti64-0.2 wt\% $\mathrm{B}_{4} \mathrm{C}$. The gear is currently with ITAMCO for machining of the band and the gear teeth with the teeth containing the Ti64-TiB composite for enhanced wear resistance. To establish the utility of such an approach more in-depth studies are required in terms of measurement of wear resistance of the Ti64-TiB region, although there is data in literature substantiating the improvements in wear resistance due to TiB. However, in higher volume fractions, TiB can negatively impact fatigue strength. Thus, future work would involve hot isostatic pressing (HIP) of such gear components followed by high cycle fatigue testing at a component level that is beyond the scope of the study. The current study does demonstrate, that hybrid materials can be leveraged to make lightweight wear resistant gear components.

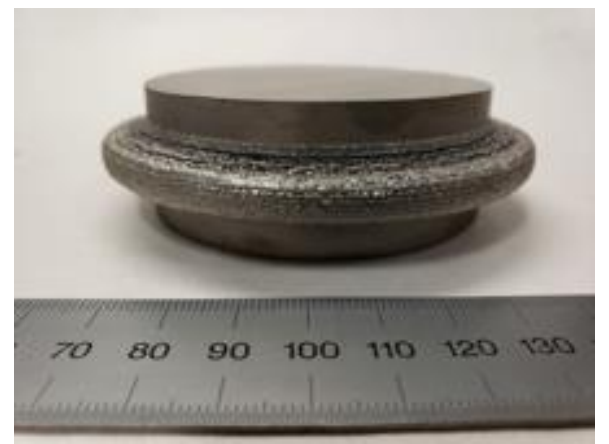

Figure 5 shows the graded Ti64/Ti64- $\mathrm{B}_{4} \mathrm{C}$ band deposited on a pure Ti64 bar stock that will be machined to final gear morphology

\subsection{IMPACTS}

This project has successfully demonstrated that by combining conventional components such as bar stock material, that can be obtained for lower price points, with additive manufacturing there is a potential to revolutionize the way gears are fabricated, especially for specialized industry sectors where lower weight and high wear resistance are prioritized. Furthermore, hybrid materials have the potential to enhance the component life i.e. in the current case the gear toughness is maintained by having a Ti64 hub while enhancing the wear resistance by fabricating Ti64-B ${ }_{4} \mathrm{C}$ composite band and teeth regions. Irrespective of the AM technology, typically gear components will need machining to final surface finish. Thus, making hybrid gear bands and teeth atop conventionally fabricated gear hub has the potential to make economical gears compared to those attained by other AM technologies.

\subsection{CONCLUSIONS}

In conclusion ORNL and ITAMCO have demonstrated that additive manufacturing has the potential to reduce gear weights by either fabricating topology optimized gears, that could be more expensive than traditional gears but lighter, or by an innovative coupling of traditional and additive manufacturing to make hybrid gears that could be closer to the price point of traditional gears but offering tremendous improvement in material behavior. At this point, further studies are warranted to establish the 
merit of such designs, especially via component level testing.

\section{ITAMCO BACKGROUND}

ITAMCO is a technology and manufacturing company focused on innovative solutions ranging from traditional manufacturing to additive manufacturing for industrial, oil and gas, mining, and defense and government sectors. They also provide custom gearbox and assembly services for relevant industry sectors. More recently ITAMCO has also added additive manufacturing capabilities to enhance their business case and capture more markets. 